Sādhanā Vol. 37, Part 2, April 2012, pp. 207-222. (C) Indian Academy of Sciences

\title{
Enhancement of cell characteristics via baffle blocks in a proton exchange membrane fuel cell
}

\author{
ATILLA BIYIKOGLU ${ }^{\mathrm{a}, *}$ and HÜLYA OZTOPRAK ${ }^{\mathrm{b}}$ \\ ${ }^{a}$ Mechanical Engineering Department, Faculty of Engineering, Gazi University, \\ Celal Bayar Boulevard, 06570 Maltepe, Ankara, Turkey \\ ${ }^{\mathrm{b}}$ General Directorate of Educational Technology, Ministry of Education, \\ Ankara, Turkey \\ e-mail: abiyik@gazi.edu.tr
}

MS received 25 December 2010; revised 28 June 2011; accepted 26 July 2011

\begin{abstract}
In this study, the effects of baffle blocks located in the flow channel on fuel cell characteristics were investigated. The higher current densities were obtained from the cells with blockage than without blockage. It was observed that the gap between the tip of the baffle block and the channel wall had a significant effect on the current density produced and on the convergence of solutions. The number and the size of blocks that are providing the highest current density from the cell were determined. No significant effects were observed in the polarization curves for cells with more than four blocks and gap ratio of 0.3 . A parametric study was conducted to investigate the effect of the relative humidity and velocity of inlet gases on cells with four blocks and gap ratio of 0.3 . It was concluded that the current density is strongly dependent on the relative humidity for low inlet velocities and on the other hand, on the inlet velocity for low relative humidities.
\end{abstract}

Keywords. Fuel cell; baffle block; polarization curves; parametric study.

\section{Introduction}

Fuel cells are one type of device to produce green energy from fossil fuels in future applications. However, there are some problems must be overcome for the lasting development of fuel cells. For example, the usage ratio of hydrogen fuel must be increased. One possible way to increase the usage ratio is to increase the residence time and use momentum by changing the direction of the fuel for more effective usage in the fuel cell. It seems that this can be achieved by placing baffle blocks in the flow direction of the fuel through the flow channels. There are numerous works on the development of the fuel usage ratio proposing different geometrical arrangements in the flow channels of fuel cells. The following studies have been selected from the literature to relate the state-of-the-art in this field.

*For correspondence 
Soong et al (2005) proposed a novel configuration of a partially blocked fuel channel with baffle plates transversely inserted in the channel. The effects of the blockage with various gap ratios and numbers of baffle plates, the fuel flow Reynolds number, and the porosity of the diffusion layer on the reactant gas transport and the pressure drop across the channel length were explored. A two-dimensional model of a one-sided porous-walled channel with the presence of baffle plates was considered. An approximate analysis was performed first to examine the qualitative nature of the flow in the gap region; then, numerical simulations for the parametric study of the reactant gas transport in a half-cell model were carried out. The velocity field, the oxygen mass flux/flow rate reaching the catalyst layer, the concentration of the water vapor produced, the fraction of the fuel gas entering the diffusion layer, and the pressure drop under various conditions were analysed. The results revealed that reducing the gap size or increasing the baffle number to enhance the reactant gas transport results in a significant loss of pressure. Among the parameters considered in the study of Soong et al (2005), the gap ratio had the most remarkable affect on the variation of the pressure drop. High pressure losses could be generated due to the high flow resistance at a low gap ratio combined with a low gas diffusion layer (GDL) porosity. Considering the requirements of good performance and a reasonable pressure drop, the results indicated that designs with a baffle gap ratio no smaller than 0.1 , with $N=3-5$ baffle plates, and a GDL porosity around 0.7 seemed quite appropriate.

In the work of Liu et al (2006), the objective was to examine the reactant gas transport and the cell performance of a proton exchange membrane fuel cell (PEMFC) with a tapered flow channel design. It was expected that, with the reduction in the channel depth along the stream-wise direction, the reactant fuel gas in the tapered channel could be accelerated and forced into the gas diffuser layer to enhance the electrochemical reaction and thus augment the cell performance. The effects of liquid water formation on the reactant gas transport were taken into account in the study of Liu et al (2006). Numerical predictions showed that the cell performance could be enhanced by tapering the fuel channel, and the enhancement was more noticeable at lower voltages. The results also revealed that the liquid water effect, in general, influences the cell performance, and the effect becomes more significant at lower voltages.

Jang et al (2006) examined the effects of the baffle number and humidity of the reactant fuel at the inlet on the detailed gas transport and cell performance of PEM fuel cells with baffle-blocked flow field designs. Due to the blockage effects in the presence of the baffles, more fuel in the flow channel could be forced into the gas diffuser layer (GDL) and catalyst layer (CL) to enhance the chemical reactions and thus augment the performance of the PEMFC systems. The effect of liquid water formation on the reactant gas transport was taken into account in the numerical modelling. Predictions showed that the local transport of the reactant gas, the local current density generation and the cell performance could be enhanced by the presence of the baffles. A physical interpretation for the difference in the inlet relative humidity $(\mathrm{RH})$ effects at high- and low-operating voltages was presented. The results revealed that, at low voltages, the liquid water effect is especially significant and should be considered in the modelling. The cell performance could be enhanced at a higher inlet relative humidity, which delays the mass transport loss thus considerably raising the limiting current density.

Wang et al (2007a) developed three-dimensional models of proton exchange membrane fuel cells (PEMFCs) with parallel and interdigitated flow channel designs including the effects of liquid water formation on the reactant gas transport. The models were used to investigate the effects of the flow channel area ratio and the cathode flow rate on the cell performance and local transport characteristics. They observed that the optimal performance for the interdigitated flow channel design occurs for a flow channel area ratio of 0.4 . 
In another study by Wang et al (2007b), a novel serpentine-baffle flow field (SBFF) design was proposed to improve the cell performance of a conventional serpentine flow field (SFF). The results show that at high operating voltages, the conventional design and the baffled design have the same performance, because the electrochemical rate is low and only a small amount of oxygen is consumed, so the oxygen transport rates for both designs are sufficient to maintain the reaction rates. However, at low operating voltages, the baffled design shows better performance than the conventional design. Analyses of the local transport phenomena in the cell indicate that the baffled design induces larger pressure differences between adjacent flow channels over the entire electrode surface than the conventional design, enhancing under-rib convection through the electrode porous layer.

Yan et al (2008) developed a three-dimensional fuel-cell model to analyse the effects of the contraction ratios of height and length on the cell performance in a PEM fuel cell with serpantine flow field. The predictions show that the cell performance is improved by increments in the length of the reduced flow area, besides greater decrements in the outlet flow area. If the power losses due to pressure drops are not considered, the cell performance with the contracted outlet channel flow areas continues to improve as the outlet flow areas are reduced and the lengths of the reduced flow areas are increased. When the pressure losses are also taken into account, the optimal performance is obtained at a height contraction ratio of 0.4 and a length contraction ratio of 0.4 in the present design.

Wang et al (2008a) developed a 3D numerical model to explore the effects of the cathode flow channel configuration on the local transport phenomena and cell performance for parallel and interdigitated flow fields in proton exchange membrane (PEM) fuel cells. For operating voltages greater than $0.7 \mathrm{~V}$, the flow channel aspect ratio and the flow channel cross-sectional area have little effect on the cell performance. For operating voltages lower than $0.7 \mathrm{~V}$, as the operating voltage decreases the electrochemical reaction rates gradually increase with a large amount of oxygen consumption and liquid water production, so the cell performance is strongly dependent on the flow field design. For the parallel flow field design, lower flow channel aspect ratios and flowchannel cross-sectional areas improve liquid water removal, thus, decreasing both improves cell performance. However, the interdigitated design has an optimal aspect ratio of 1.00 and an optimal cross-sectional area of $1.000 \times 1.000 \mathrm{~mm}$.

Wang et al (2008b) investigated the effects of the relative humidity (RH) of the reactants on the cell performance and local transport phenomena in proton exchange membrane fuel cells with parallel and interdigitated flow fields. The authors also indicated that with a constant anode $\mathrm{RH}=100 \%$, for lower operating voltages, a lower cathode $\mathrm{RH}$ reduces cathode flooding and improves cell performance, while for higher operating voltages, a higher cathode RH maintains the membrane hydration to give better cell performance. It was also obtained that with a constant cathode $\mathrm{RH}=100 \%$, for lower operating voltages, a lower anode RH not only provides more hydrogen to the catalyst layer to participate in the electrochemical reaction, but also increases the difference in the water concentrations between the anode and cathode, which enhances backdiffusion of water from the cathode to the anode, thus reducing cathode flooding to give better performance. However, for higher operating voltages, the cell performance is not dependent on the anode RH.

In this study, the effects of blockage on the PEM fuel cell characteristics were investigated. Polarization curves were constructed for different numbers of baffle blocks and gap ratios. Based on the cell characteristics, the optimal gap ratio and the number of baffle blocks were determined. A parametric study was performed to observe the effects of humidity and velocity of the inlet gases on cell characteristics for both the anode and cathode sides of the PEM fuel cell. 


\section{Description of the problem}

The PEM fuel cell under investigation is composed of eleven parts. The names of the parts and a schematic frontal view are shown in figure 1, and part numbers and an isometric view of a single cell are shown in figure 2 . Five parts are on the anode side, and the corresponding parts are symmetrically placed on the cathode side, namely, the anode and cathode catalyst layers $\left(5,5^{\prime}\right)$, gas diffusion layers $\left(4,4^{\prime}\right)$, gas channels $\left(3,3^{\prime}\right)$, baffle blocks $\left(2,2^{\prime}\right)$, bipolar current collectors $\left(1,1^{\prime}\right)$ and membrane (6) on the geometrical symmetry plane. The solution domain is the whole cell geometry, including the anode and cathode sides. Baffle blocks are attached to the faces of the current collectors at the midpoints of the gas channels.

The dimensions of the PEM fuel cell parts are listed in table 1. The Membrane Electrode Assembly (MEA), which includes the membrane, catalyst layers and gas diffusion layers, has an active surface area of $0.21 \mathrm{~cm}^{2}$. The total cell volume is width, height and length$3 \times 4.7 \times 70 \mathrm{~mm}^{3}$. The physical properties of the PEM fuel cell components may be found in the thesis of Alpat (2007). The catalyst layer properties were selected to be a combination of platinum and graphite properties to increase the rates of electrochemical reactions both on the anode and cathode sides due to the low operating temperatures in the PEM fuel cell. The bipolar plates were constructed of graphite due to its high electrical conductivity. The gas diffusion layers were composed of Toray TGP-H-060. Nafion was selected as the membrane material. The electrochemical parameters of the cell were introduced into the PEMFC module of Fluent, and these data may be viewed in the work of Biyikoglu \& Oztoprak (2010).

\subsection{Mathematical model}

The mathematical model was constructed for the transport of quantities inside the PEM fuel cell. The fuel cell operation was governed by the mass, momentum, species and charge conservation equations, which were applied in Fluent 6.2 with a single domain formulation, and may

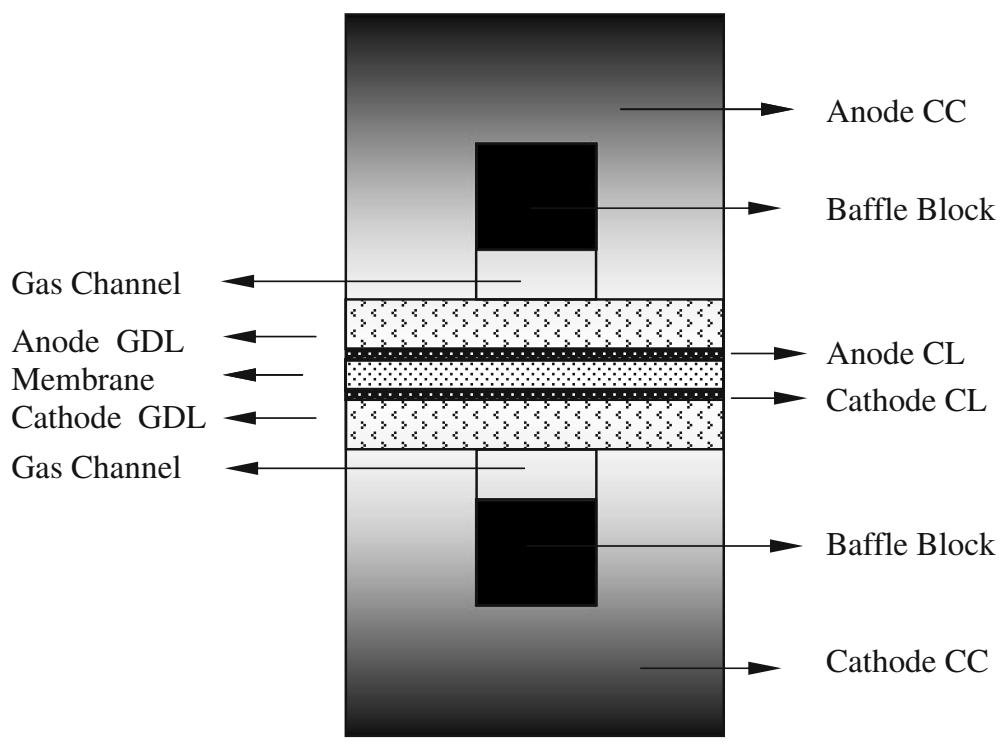

Figure 1. Schematic front view of the PEM fuel cell. 


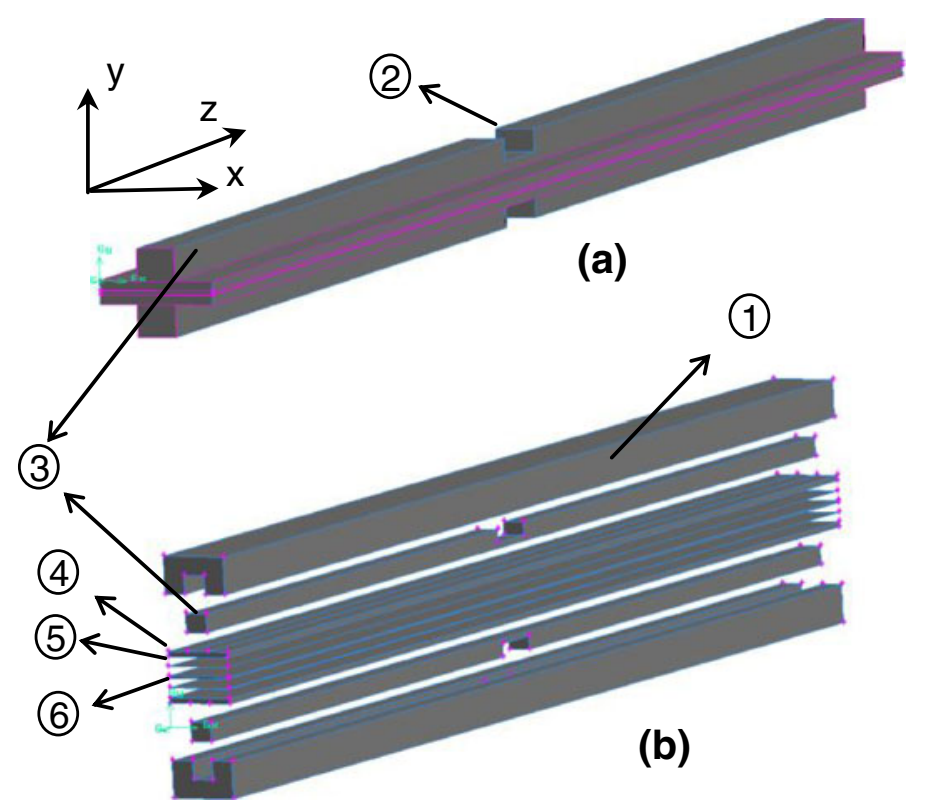

Figure 2. Isometric view of PEM fuel cell from Gambit module; (a) Membrane electrode assembly with gas channels, (b) Pre-assembly of single cell.

also be found in the thesis of Oztoprak (2007). In the PEM fuel cell model of FLUENT, two electric potential fields were solved; the first one was solved in the membrane and catalyst layers, and the second one was solved in the catalyst layers, diffusion layers, and current collectors. Heterogeneous reactions were assumed to occur at the surface of the catalyst layers. The surface reactions on the porous catalyst region were solved, and the reaction diffusion balance was applied to compute the rates. The current density was computed assuming the Butler-Volmer equality and depending on the cell voltage prescribed. In the gas channels and diffusion layers, the equations for the conservation of species, mass, momentum and energy were solved. In the diffusion layers and the membrane, which was a porous structure, Darcy's formulation was used for the conservation of momentum. The details of the model assumptions can be found in the paper of Biyikoglu \& Alpat (2010).

Table 1. Dimensions of the parts of PEM fuel cell.

\begin{tabular}{lccc}
\hline Parts & Width $(\mathrm{mm})$ & Height $(\mathrm{mm})$ & Length $(\mathrm{mm})$ \\
\hline CC & 3 & 2 & 70 \\
GC & 1 & 1 & 70 \\
GDL & 3 & 0.3 & 70 \\
CL & 3 & 0.0129 & 70 \\
Membrane & 3 & 0.108 & 70 \\
Baffle Block & 1 & 0.7 & 3 \\
PEMFC & 3 & 4.7338 & 70 \\
\hline
\end{tabular}




\subsection{Boundary conditions}

In this study, the mass flow inlet and pressure outlet boundary conditions were assigned at the inlet and outlet ports of the anode and cathode gas channels, respectively. The wall boundary condition was assigned at the surfaces of the current collector that faces the gas channels and outside air. The porous jump boundary condition was assigned at the interface between the membrane and catalyst layers and between gas diffusion layers and gas channels. The details of boundary conditions that were assigned at the surfaces of each layer of the PEM fuel cell can be found in the thesis of Oztoprak (2007).

\section{Numerical method}

Hexagonal grids were used in the construction of the mesh structure. The control volume approach was used in the discretization of the conservation equations in integral form. The first order upwind method was used in the discretization of the convective terms. The implicit pressure-based (segregated) scheme (SIMPLE algorithm) and the Gauss-Seidel iterative technique (segregated solver) were used to solve the set of algebraic equations. The under-relaxation parameters for momentum and pressure were selected to be 0.3 to slow down the speed of convergence. It was assumed that the converged solution was obtained when the residual value for energy was less than $10^{-6}$ and when the residual values of all of the other solved properties were less than $10^{-4}$.

\subsection{Grid independency tests}

Grid independency tests were performed to obtain the optimal number of grid points. For this purpose, five different distributions of element numbers were determined by varying the interval size of the grid structure and the distribution of the number of grids. The aspect ratios for each layer of the PEM fuel cell are listed for five different spacing in table 2. The high aspect ratio of the problem restricted the minimum number of grids required to construct the mesh structure properly. The variation of the mean current density and the solution time with the mesh number was obtained by using the operational parameters for Case 1 and is presented in table 3 .

Tests were performed at atmospheric pressure for a cell potential of $0.88 \mathrm{~V}$. Other operational parameters were selected as follows. Hydrogen and water vapor mixture was fed to the

Table 2. Number of grid distributions for PEMFC layers with hexagonal structure at five different grid spacings.

\begin{tabular}{lcccccc}
\hline $\begin{array}{l}\text { PEMFC layers } \\
\text { (Grid spacings) }\end{array}$ & $(0.15$ & 0.2 & 0.4 & 0.5 & $0.6)$ & $\begin{array}{c}\text { Aspect } \\
\text { ratio }\end{array}$ \\
\cline { 2 - 6 } Current collectors & 209216 & 87500 & 12600 & 5600 & 3276 & 35 \\
Gas channel & 45766 & 17500 & 3150 & 1120 & 936 & 70 \\
Gas diffusion layer & 39228 & 10500 & 3150 & 1680 & 1404 & 233 \\
Catalyst layer & 19614 & 10500 & 3150 & 1680 & 1404 & 5426 \\
Membrane & 9807 & 5250 & 1575 & 840 & 702 & 648 \\
Cell & 323631 & 131250 & 18900 & 10920 & 7722 & 14.7 \\
\hline
\end{tabular}


Table 3. Mean current density values ${ }^{\mathrm{a}}$ and solution times at different number of grids.

\begin{tabular}{lcccc}
\hline $\begin{array}{l}\text { Interval } \\
\text { size }\end{array}$ & $\begin{array}{c}\text { Total no. } \\
\text { of grids }\end{array}$ & $\begin{array}{c}\text { Current density } \\
\left(\mathrm{A} \mathrm{cm}^{-2}\right)\end{array}$ & $\begin{array}{c}\text { Dev. in current } \\
\text { density }(\%)\end{array}$ & $\begin{array}{c}\text { Solution time } \\
(\mathrm{min})\end{array}$ \\
\hline 0.6 & 7722 & 0.103897 & - & 4 \\
0.5 & 10920 & 0.104735 & 0.80 & 6 \\
0.4 & 18900 & 0.104156 & 0.56 & 10 \\
0.2 & 131250 & 0.104131 & 0.03 & 84 \\
0.15 & 323631 & 0.109293 & 4.72 & 242 \\
\hline
\end{tabular}

${ }^{\text {a }}$ Solutions were obtained by using the parameters for Case 1

anode gas channels at a mass flux of $3.10 \times 10^{-6} \mathrm{~kg} \mathrm{~s}^{-1}$ and with a mass fraction of 0.11 for $\mathrm{H}_{2}$ and 0.89 for $\mathrm{H}_{2} \mathrm{O}$. Humidified air was fed to the cathode gas channels at a mass flux of $1.58 \times 10^{-6} \mathrm{~kg} \mathrm{~s}^{-1}$. Oxygen and water vapor mass fractions were taken to be 0.15 and 0.36 in air, respectively.

It can be thought that the suitable result was attained when the minimum change was observed in the current density for successive grid results and this point corresponds to 131250 grid numbers in the problem. However, one must also take into account the solution time. A combination of the effects of current density change and the solution time has led us to determine the proper grid number to be about 18900 for this problem.

\subsection{Polarization curves}

The total cell over potential was defined as the difference between the theoretical open cell voltage and the cell operating voltage. Therefore, each of the cell over-potential corresponded to a cell voltage. The current densities were computed from the numerical model corresponding to the over-potential values (cell voltage). The total cell over-potential was increased by a stepfunction, e.g., a hyperbolic relaxation function, Siegel (2003). The nine over-potential steps were determined to be $0.23,0.28,0.33,0.38,0.48,0.58,0.68,0.78$, and $0.88 \mathrm{~V}$. A polarization curve was constructed using the computed current densities and cell voltages for these nine steps, Oztoprak (2007). The results obtained from a converged solution were taken as the initial values for the solved quantities at the next solution step.

The open circuit voltages were calculated using the theoretical open circuit voltage and taking into account the voltage loss due to activation energy. The following equation was used to calculate true open circuit voltage, Larminie \& Dicks (2003).

$$
V=E-A \ln \left(\frac{i+i_{n}}{i_{o}}\right)
$$

where $i_{o}$ and $i_{n}$ represent the exchange current density and the internal current density, respectively. E was called the theoretical open circuit voltage when no current $(i)$ passes through the circuit. The theoretical open circuit voltage was calculated to be $1.18 \mathrm{~V}$ for the fuel cell, Alpat (2007). The open circuit voltage was calculated to be $0.92 \mathrm{~V}$ using Eq. (1) and taking the fuel cell parameters, such as the reference current density $\left(i_{o}=0,04 \mathrm{~mA} \mathrm{~cm}{ }^{-2}\right)$, crossover current $\left(i_{n}=3 \mathrm{~mA} \mathrm{~cm}^{-2}\right)$ and coefficient in the Tafel equation $(\mathrm{A}=0.06 \mathrm{~V})$ for the fuel cell studied. 
Table 4. Comparison of iteration numbers at 9 points in polarization curves for 9 different cases and the total number of iteration (the solution time).

\begin{tabular}{lcccccccccc}
\hline Case & P1 & P2 & P3 & P4 & P5 & P6 & P7 & P8 & P9 & Total \\
\hline 1 & 300 & 250 & 200 & 200 & 200 & 200 & 200 & - & - & 1550 \\
2 & 400 & 400 & 300 & 250 & 250 & 250 & 250 & 250 & 250 & 2600 \\
3 & 400 & 400 & 300 & 300 & 250 & 250 & 250 & 250 & 250 & 2650 \\
4 & 400 & 250 & 250 & 250 & 250 & 250 & 250 & 250 & 250 & 2400 \\
5 & 300 & 250 & 250 & 250 & 250 & 250 & 250 & 250 & 250 & 2300 \\
6 & 350 & 250 & 250 & 250 & 250 & 250 & 250 & 250 & 250 & 2350 \\
7 & 300 & 250 & 250 & 250 & 250 & 250 & 250 & 250 & 250 & 2300 \\
8 & 400 & 300 & 300 & 250 & 250 & 250 & 250 & 250 & 250 & 2500 \\
9 & 300 & 200 & 200 & 200 & 200 & 200 & 200 & 200 & 200 & 1900 \\
\hline
\end{tabular}

\subsection{Convergence criteria}

The solution was considered to converge when the residual for energy became lower than the value of $10^{-6}$ and the residual value for all other properties lower than $10^{-4}$. Polarization curves were constructed for seven successive over-potential values starting from $0.92 \mathrm{~V}$ and ending with $0.23 \mathrm{~V}$ by a step function for Case 1 . The solution converged after 1550 iterations, but the number of iterations required could be shortened to about 550 iterations by applying the successive solution methodology.

The numbers of iterations required for convergence are listed in table 4 for the nine successive points and nine different cases. The effect of the relative humidity and inlet velocity of the gases on the solution time were as follows. The solution time increased by 40 per cent when the relative humidity was decreased from $\phi=1$ (Case 1) to $\phi=0.6$ (Case 2) and increased by 2 per cent when the relative humidity was decreased from $\phi=0.6$ (Case 2) to $\phi=0.2$ (Case 3). The solution time increased by 35 per cent when the inlet velocity of the gases was decreased from $v=1.75 \mathrm{~m} \mathrm{~s}^{-1}$ (Case 1) to $v=0.7 \times 1.75 \mathrm{~m} \mathrm{~s}^{-1}$ (Case 4) and decreased by 4 per cent when the inlet velocity of the gases was decreased from $v=0.7 \times 1.75 \mathrm{~m} \mathrm{~s}^{-1}$ (Case 4) to $v=0.2 \times 1.75 \mathrm{~m} \mathrm{~s}^{-1}$ (Case 5). When the inlet velocities of the gases for both the anode and cathode sides were equal to $v=0.7 \times 1.75 \mathrm{~m} \mathrm{~s}^{-1}$, decreasing the relative humidity from $\phi=1$ (Case 4 ) to $\phi=0.6$ (Case 6) resulted in a decrease in the total iteration number by 3 per cent, and on the other hand, decreasing the relative humidity from $\phi=0.6$ (Case 6) to $\phi=0.2$ (Case 8 ), resulted in an increase in the total iteration number by 6 per cent. When the inlet velocites of the gases for both the anode and cathode sides were equal to $v=0.2 \times 1.75 \mathrm{~m} \mathrm{~s}^{-1}$, decreasing the relative humidity from $\phi=1$ (Case 5) to $\phi=0.6$ (Case 7) resulted in no change in the total iteration number, however decreasing the relative humidity from $\phi=0.6$ (Case 7) to $\phi=0.2$ (Case 9) decreased the total iteration number by 21 per cent.

\section{Results and discussion}

In this study, solutions were obtained for nine different cases by using the Fluent PEM fuel cell module, as shown in table 5. As a result of grid independency tests, it was concluded that using 18900 grids is sufficient to obtain a grid independent solution. The operational parameters for these nine cases in table 5 were converted to the data required by the Fluent PEMFC module and are listed in table 6. The calculation details can be found from the thesis of Oztoprak (2007). The solver data were obtained on a computer with a $1.86 \mathrm{GHz}$ Pentium 4 and is presented in table 7. 
Table 5. Operational Parameters ${ }^{\mathrm{b}}$ for the investigated 9 cases (Jang et al 2006).

\begin{tabular}{lcc}
\hline $\begin{array}{l}\text { Case } \\
\text { No }\end{array}$ & $\begin{array}{c}\text { Rel. humidity, } \phi \\
{[\%]}\end{array}$ & $\begin{array}{c}\text { Velocity, } v \\
{[\mathrm{~m} / \mathrm{s}]}\end{array}$ \\
\hline 1 & 1 & 1.75 \\
2 & 0.6 & 1.75 \\
3 & 0.2 & 1.75 \\
4 & 1 & $0.7 \times 1.75$ \\
5 & 1 & $0.2 \times 1.75$ \\
6 & 0.6 & $0.7 \times 1.75$ \\
7 & 0.6 & $0.2 \times 1.75$ \\
8 & 0.2 & $0.7 \times 1.75$ \\
9 & 0.2 & $0.2 \times 1.75$ \\
\hline
\end{tabular}

${ }^{\mathrm{b}}$ Solutions were obtained at atmospheric pressure and temperature of $80^{\circ} \mathrm{C}$

In order to observe the effects of baffle blocks on mass transfer limitation clearly, activation losses and ohmic losses are minimized by selecting proper parameters in the numerical model.

\subsection{Determination of the block height and number}

In this study, to determine the block height that maximizes the current density produced, six different gap ratios $\lambda$, which is the ratio of gap between the block tip and channel wall $\mathrm{h}_{2}$ to the channel height $\mathrm{h}_{1}$, were selected, namely, $\lambda=h_{2} / h_{1}=0.1,0.2,0.3,0.4,0.5$ and 1.0. Polarization curves were constructed for the gap ratios with and without blockage $(\lambda=1.0)$. In these trials, the operational parameters were taken to be the same as in the grid independency tests. The results are presented in figure 3.

The highest and the lowest current densities were obtained for gap ratios of 0.1 and 1 , respectively. The current densities for gap ratios of $0.1,0.2$ and 0.3 were much closer to each other than

Table 6. Operational parameters ${ }^{\mathrm{c}}$ for fluent PEMFC module.

\begin{tabular}{lcccccc}
\hline Case No & \multicolumn{2}{c}{$\begin{array}{c}\text { Mass flux }\left[\mathrm{kg} \mathrm{s}^{-1}\right] \\
\text { (Anode) }\end{array}$} & \multicolumn{5}{c}{$\begin{array}{c}\text { Mass fraction } \\
\text { (Cathode) }\end{array}$} & \multicolumn{2}{c}{ (Anode) } & (Cathode) \\
\cline { 4 - 7 } & & & $\mathrm{H}_{2}$ & $\mathrm{H}_{2} \mathrm{O}$ & $\mathrm{O}_{2}$ & $\mathrm{H}_{2} \mathrm{O}$ \\
\hline 1 & $3.0979 \times 10^{-6}$ & $1.5771 \times 10^{-6}$ & 0.113 & 0.887 & 0.1494 & 0.3561 \\
2 & $8.7565 \times 10^{-6}$ & $1.2641 \times 10^{-6}$ & 0.2229 & 0.7771 & 0.1864 & 0.1966 \\
3 & $9.6832 \times 10^{-6}$ & $1.0812 \times 10^{-6}$ & 0.5203 & 0.4797 & 0.2180 & 0.0607 \\
4 & $2.1685 \times 10^{-6}$ & $1.1040 \times 10^{-6}$ & 0.113 & 0.887 & 0.1494 & 0.3561 \\
5 & $6.1958 \times 10^{-7}$ & $1.1040 \times 10^{-6}$ & 0.113 & 0.887 & 0.1494 & 0.3561 \\
6 & $6.1295 \times 10^{-6}$ & $8.8488 \times 10^{-7}$ & 0.2229 & 0.7771 & 0.1864 & 0.1966 \\
7 & $1.7519 \times 10^{-6}$ & $2.5282 \times 10^{-7}$ & 0.2229 & 0.7771 & 0.1864 & 0.1966 \\
8 & $6.7782 \times 10^{-6}$ & $7.5684 \times 10^{-7}$ & 0.5203 & 0.4797 & 0.2180 & 0.0607 \\
9 & $1.9366 \times 10^{-6}$ & $2.1624 \times 10^{-7}$ & 0.5203 & 0.4797 & 0.2180 & 0.0607 \\
\hline
\end{tabular}

${ }^{\mathrm{c}}$ Operational pressure is atmospheric pressure for all 9 cases 
Table 7. Solver data.

\begin{tabular}{lc}
\hline Solver data & Values \\
\hline Total mesh number & 18900 \\
RAM-used/RAM-available & $590 / 760 \mathrm{MB}$ \\
Total iteration number & 400 \\
Mean time per one iteration & 4 seconds \\
Total iteration time & 3720 seconds $(1 \mathrm{~h})$ \\
Required time for 7 point polarization curve & 434 minutes $(7 \mathrm{~h})$ \\
\hline
\end{tabular}

to the higher gap ratios, and there was a discrepancy between the current densities for gap ratios of 0.3 and 0.4 . It was thought that it may be reasonable to study cells with only a gap ratio of 0.3 . Therefore, the number of baffle blocks that maximizes the current density was determined for a cell with a gap ratio of 0.3 . The results are presented in figure 4 to show the effect of the number of blocks on the current density and cell voltage. The results are shown for nine different cases with block numbers ranging from one to nine. Using the parameters of Case 1, the lowest and the highest current densities were obtained for the channel without blockage and with the block numbers of one and nine, respectively. It can be clearly seen in figure 4 that using more than four blocks do not change the current density considerably. Therefore, there is no need to use more than four blocks. The current density could not increase above $1.58 \mathrm{~A} \mathrm{~cm}^{-2}$ due to mass transfer limitations.

\subsection{Parametric study with the proper configuration}

This section is devoted to the investigation of the effect of the relative humidity and the inlet velocity of the reactant gases on the polarization curves for cells with a gap ratio of 0.3 and a block number of four. The open circuit potential was reduced from 1.18 to $0.92 \mathrm{~V}$ due to activation losses (Oztoprak 2007). It was shown that the change in the relative humidity had no effect on the open circuit potential and activation losses.

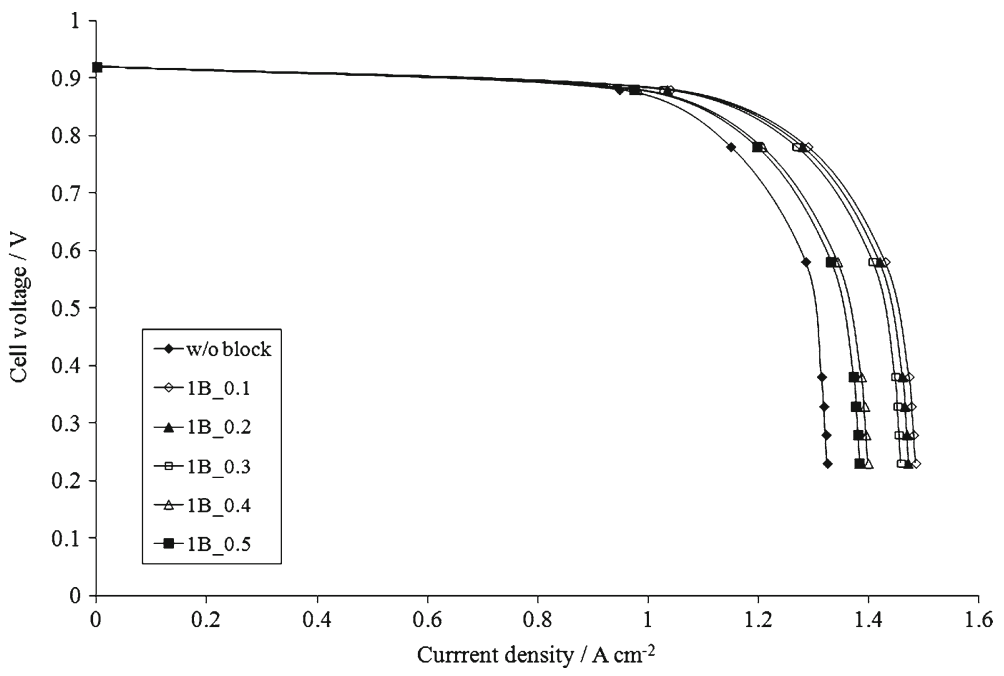

Figure 3. Polarization curves for different gap ratios. 


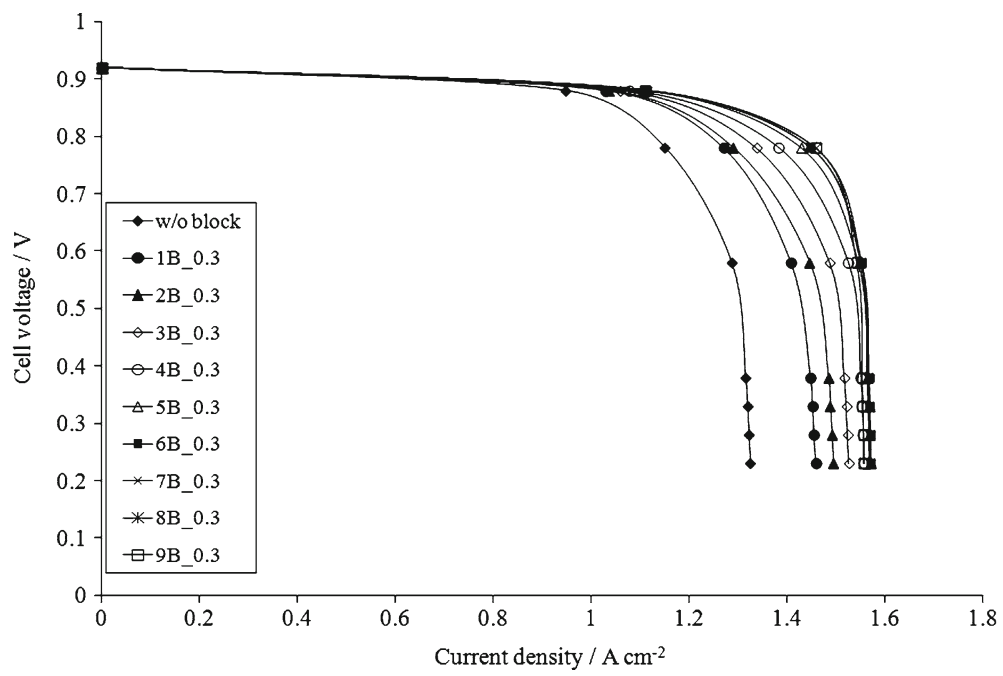

Figure 4. Polarization curves for different block numbers.

The effect of the relative humidity on the current density is presented in figure 5 for the inlet velocity $v=1.75 \mathrm{~m} \mathrm{~s}^{-1}$ for three cases, namely, Case 1, Case 2 and Case 3 . Tracking the polarization curves in figure 5 for Case 1, Case 2 and Case 3 simultaneously, one can observe that the difference between the current densities of Case 1 and Case 2 decreased, on the other hand, the difference between the current densities of Case 2 and Case 3 increased up to a cell voltage of $0.58 \mathrm{~V}$ and then decreased as the cell potential was decreased. The maximum current density at the lowest voltage reached $1.58 \mathrm{~A} \mathrm{~cm}^{-2}$ for $\phi=1$ (Case 1). The maximum current density at the lowest voltage resulted in a decrease by 1.3 per cent when the relative humidity was decreased

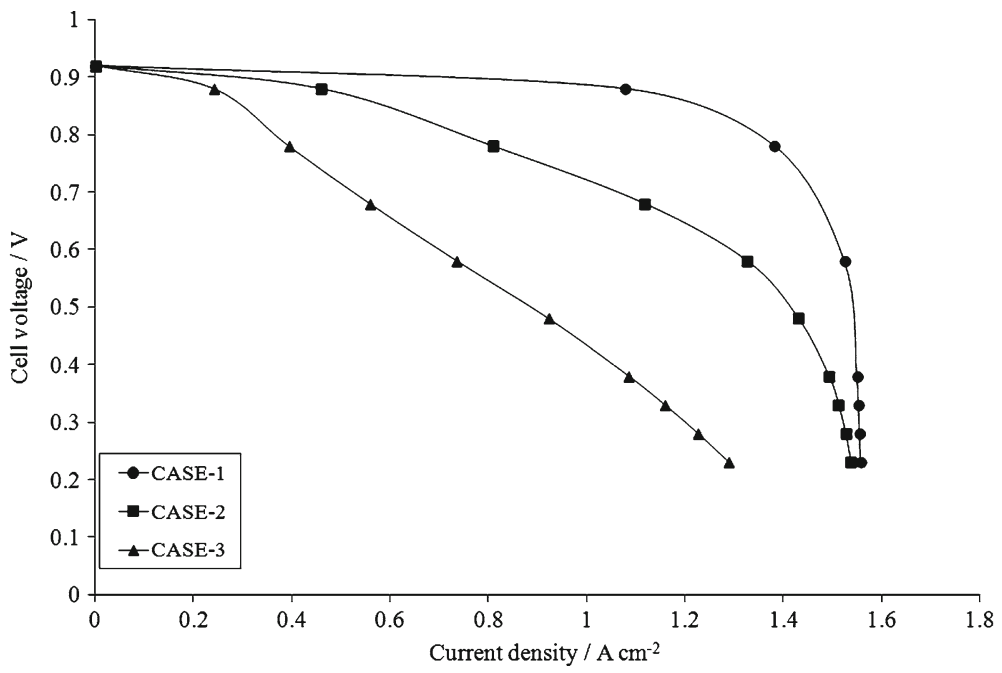

Figure 5. The effect of relative humidity on polarization curves at the inlet velocity of $v=1.75 \mathrm{~m} \mathrm{~s}^{-1}$; $\phi=1$ (Case 1), $\phi=0.6$ (Case 2), $\phi=0.2$ (Case 3). 


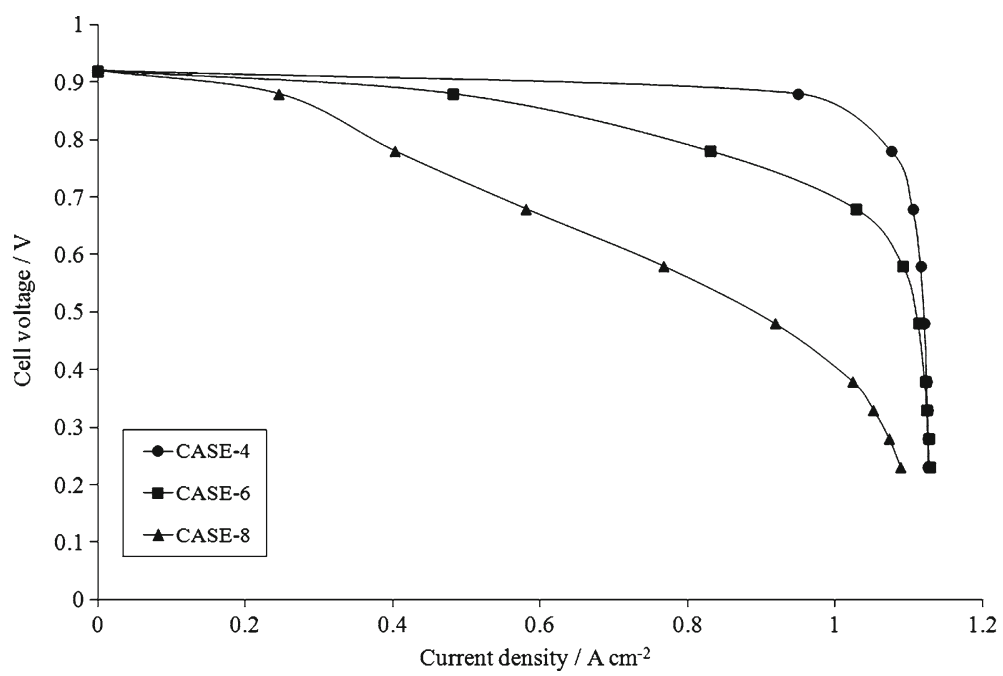

Figure 6. The effect of relative humidity on polarization curves at the inlet velocity of $v=0.7 \times$ $1.75 \mathrm{~m} \mathrm{~s}^{-1} ; \phi=1$ (Case 4), $\phi=0.6$ (Case 6), $\phi=0.2$ (Case 8).

from $\phi=1$ (Case 1 ) to $\phi=0.6$ (Case 2) and a decrease by 19.2 per cent when the relative humidity is decreased from $\phi=0.6$ (Case 2) to $\phi=0.2$ (Case 3).

The effect of the relative humidity on the current density is presented in figure 6 for an inlet velocity $v=0.7 \times 1.75 \mathrm{~m} \mathrm{~s}^{-1}$ for three cases, namely, Case 4, Case 6 and Case 8 . Tracking the polarization curves in figure 6 for Case 4, Case 6 and Case 8 simultaneously, one can see that the difference between the current density for Case 4 and Case 6 decreased as the cell potential was decreased, the difference between the current densities for Case 6 and Case 8 increased up to a cell voltage of $0.68 \mathrm{~V}$ and then decreased as the cell potential was decreased. The maximum

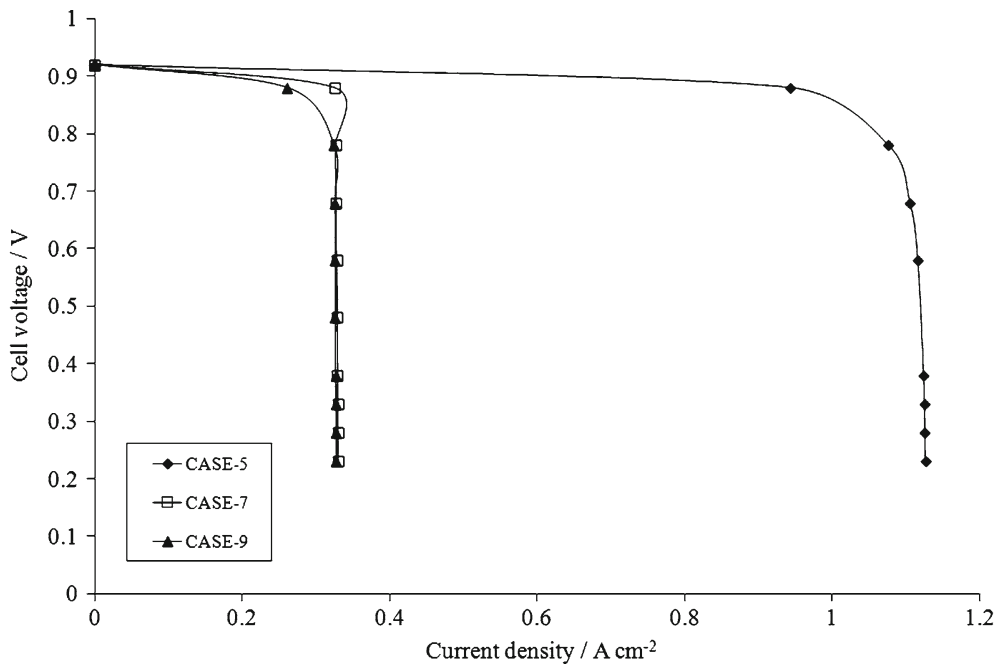

Figure 7. The effect of relative humidity on polarization curves at the inlet velocity of $v=0.2 \times$ $1.75 \mathrm{~m} \mathrm{~s}^{-1} ; \phi=1$ (Case 5), $\phi=0.6$ (Case 7), $\phi=0.2$ (Case 9). 
current densities at cell voltages of $0.23,0.28,0.33$ and $0.38 \mathrm{~V}$ had the same value $\left(1.12 \mathrm{~A} \mathrm{~cm}^{-2}\right)$ for relative humidity of $\phi=1$ (Case 4 ) and $\phi=0.6$ (Case 6). The maximum current density at the lowest cell voltage of $0.23 \mathrm{~V}$ decreased by 3.6 per cent as the relative humidity was decreased from $\phi=0.6$ (Case 6) to $\phi=0.2$ (Case 8).

The effect of the relative humidity on the current density is presented in figure 7 for an inlet velocity $v=0.2 \times 1.75 \mathrm{~m} \mathrm{~s}^{-1}$ for three cases, namely, Case 5, Case 7 and Case 9 . Tracking the polarization curves in figure 7 for Case 5, Case 7 and Case 9 simultaneously, one can see that the difference in current densities in Case 7 and Case 9 increased to the cell voltage of $0.87 \mathrm{~V}$ and then decreased to the cell voltage of $0.78 \mathrm{~V}$ and then merged, reaching a maximum current density of $0.32 \mathrm{~A} \mathrm{~cm}^{-2}$. The maximum current density at the lowest cell voltage was $1.12 \mathrm{~A}$ $\mathrm{cm}^{-2}$ for the relative humidity $\phi=1$ (Case 5). The maximum current density at the lowest cell voltage increased by 3.5 times as the relative humidity was increased from (Case 7) to $\phi=1$ (Case 5).

The effect of the inlet velocity of the gases on the current density is presented in figure 8 for a relative humidity $\phi=1$ for three cases, namely, Case 1, Case 4 and Case 5. Tracking the polarization curves in figure 8 for Case 1, Case 4 and Case 5 simultaneously, one can see that the difference between the current densities of Case 1 and Case 4 increased, while the cell potential was decreased. It can be seen that the polarization curves for the inlet velocities $v=0.7 \times 1.75 \mathrm{~m} \mathrm{~s}^{-1}$ (Case 4) and $v=0.2 \times 1.75 \mathrm{~m} \mathrm{~s}^{-1}$ (Case 5) exactly matched with each other. Therefore, it can be concluded that the inlet velocity had no effect on current density when the inlet velocity was below $v=0.7 \times 1.75 \mathrm{~m} \mathrm{~s}^{-1}$ under the saturated condition. The maximum current density at the lowest cell voltage was $1.56 \mathrm{~A} \mathrm{~cm}^{-2}$ for an inlet velocity $v=1.75 \mathrm{~m} \mathrm{~s}^{-1}$ (Case 1), and decreased by 23.4 per cent when the inlet velocity was decreased to $v=0.7 \times$ $1.75 \mathrm{~m} \mathrm{~s}^{-1}$ (Case 4).

The effect of the inlet velocity of the gases on the current density is presented in figure 9 for a relative humidity $\phi=0.6$ for three cases, namely, Case 2, Case 6 and Case 7. Tracking the polarization curves in figure 9 for Case 2, Case 6 and Case 7 simultaneously, one can see that the curves followed the same line until the cell voltage reached $0.75 \mathrm{~V}$, and then the paths changed so that at the lowest cell voltage, the greatest voltage difference was observed between Case 1

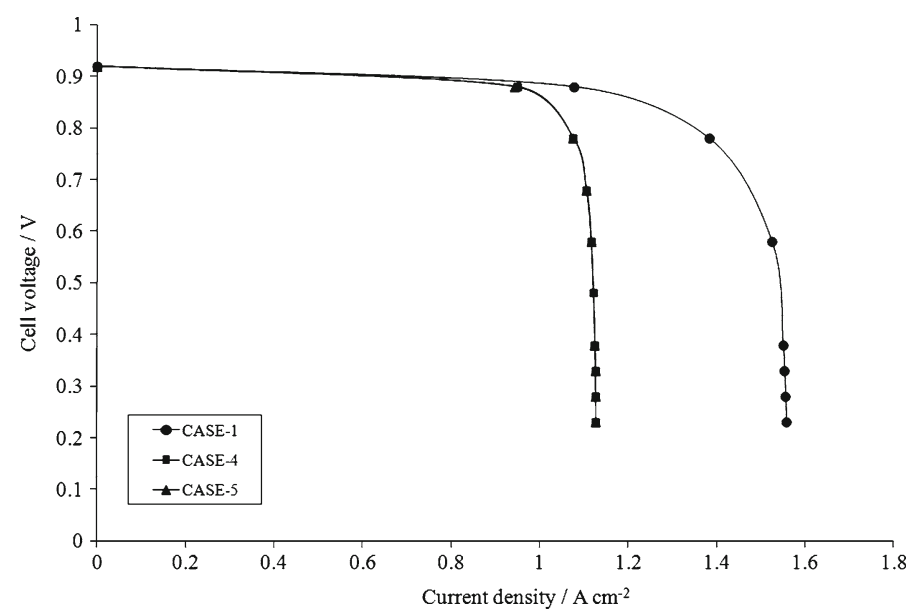

Figure 8. The effect of inlet velocity on polarization curves at the relative humidity of $\phi=1 ; v=$ $1.75 \mathrm{~m} \mathrm{~s}^{-1}$ (Case 1), $v=0.7 \times 1.75 \mathrm{~m} \mathrm{~s}^{-1}$ (Case 4) and $v=0.2 \times 1.75 \mathrm{~m} \mathrm{~s}^{-1}$ (Case 5). 


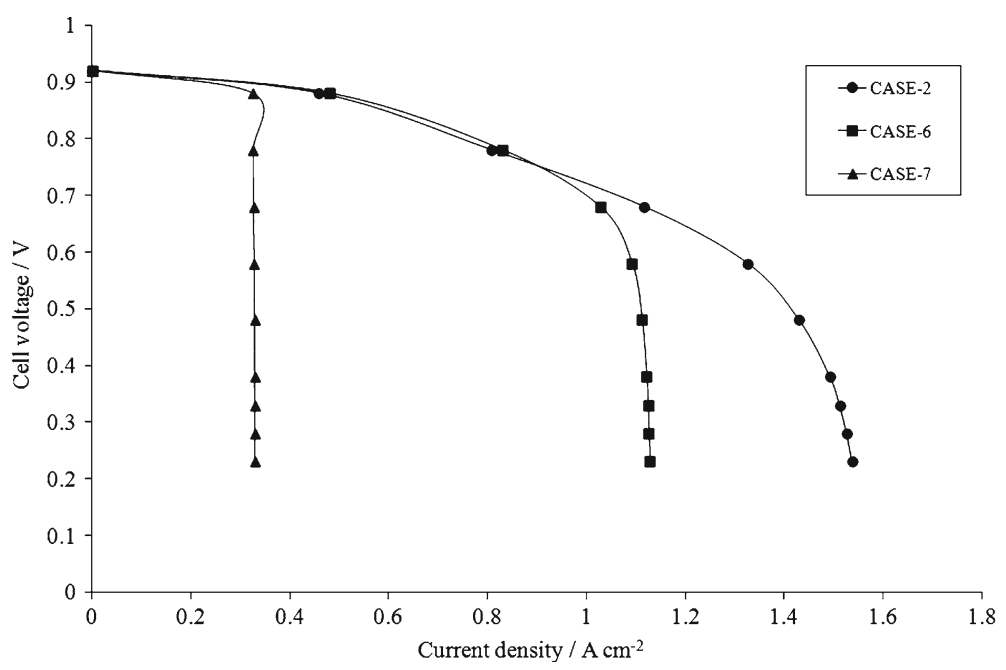

Figure 9. The effect of inlet velocity on polarization curves at the relative humidity of $\phi=0.6 ; v=$ $1.75 \mathrm{~m} \mathrm{~s}^{-1}$ (Case 2), $v=0.7 \times 1.75 \mathrm{~m} \mathrm{~s}^{-1}$ (Case 6) and $v=0.2 \times 1.75 \mathrm{~m} \mathrm{~s}^{-1}$ (Case 7).

and Case 6. The maximum current density at the lowest cell voltage was $1.56 \mathrm{~A} \mathrm{~cm}^{-2}$, which was achieved with an inlet velocity $v=1.75 \mathrm{~m} \mathrm{~s}^{-1}$ (Case 2). The maximum current density at the lowest cell voltage was decreased by 28 per cent when the inlet velocity was decreased from $v=1.75 \mathrm{~m} \mathrm{~s}^{-1}$ (Case 2) to $v=0.7 \times 1.75 \mathrm{~m} \mathrm{~s}^{-1}$ (Case 6). The maximum current density at the lowest cell voltage was decreased by 71 per cent when the inlet velocity was decreased from the value of $v=0.7 \times 1.75 \mathrm{~m} \mathrm{~s}^{-1}$ (Case 6) to $v=0.2 \times 1.75 \mathrm{~m} \mathrm{~s}^{-1}$ (Case 7).

The effect of the inlet velocity of the gases on the current density is presented in figure 10 for a relative humidity $\phi=0.2$ for three cases, namely, Case 3, Case 8 and Case 9. Tracking the

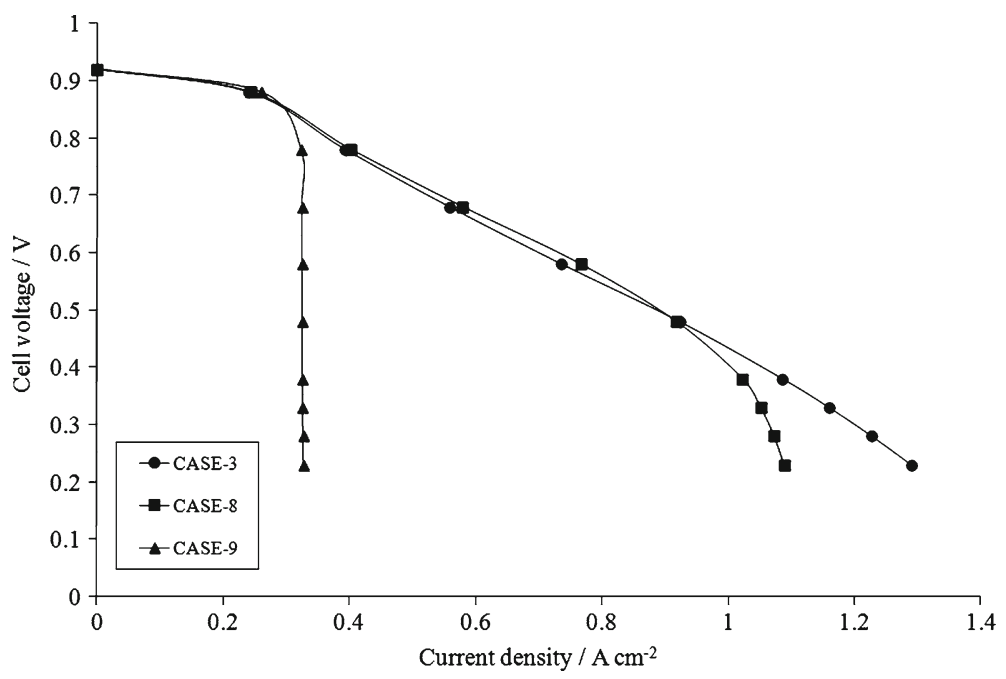

Figure 10. The effect of inlet velocity on polarization curves at the relative humidity of $\phi=0.2 ; v=$ $1.75 \mathrm{~m} \mathrm{~s}^{-1}$ (Case 3), $v=0.7 \times 1.75 \mathrm{~m} \mathrm{~s}^{-1}$ (Case 8) and $v=0.2 \times 1.75 \mathrm{~m} \mathrm{~s}^{-1}$ (Case 9). 
polarization curves in figure 10 for Case 3, Case 8 and Case 9 simultaneously, one can observe that the curves followed the same line up to a cell voltage of $0.47 \mathrm{~V}$ and then paths changed, making a maximum difference between current densities for Case 3 and Case 8 at the lowest cell voltage. The maximum current density at the lowest cell voltage was $1.30 \mathrm{~A} \mathrm{~cm}^{-2}$ for an inlet velocity $v=1.75 \mathrm{~m} \mathrm{~s}^{-1}$ (Case 3 ). The maximum current density at the lowest cell voltage decreased by 15 per cent when the inlet velocity was decreased from $v=1.75 \mathrm{~m} \mathrm{~s}^{-1}$ (Case 3 ) to $v=0.7 \times 1.75 \mathrm{~m} \mathrm{~s}^{-1}$ (Case 8 ). The maximum current density at the lowest cell voltage decreased by 72 per cent when the inlet velocity was decreased from $v=0.7 \times 1.75 \mathrm{~m} \mathrm{~s}^{-1}$ (Case 8) to $v=0.2 \times 1.75 \mathrm{~m} \mathrm{~s}^{-1}$ (Case 9).

\section{Conclusion}

In this study, a PEM fuel cell model that was constructed using the Fluent- PEMFC module was solved for nine different cases with grid number of 18900 . When baffle blocks were used, it was observed that the current density produced was increased by up to 16 per cent compared to that produced by a cell without blockage. Inserting more than four baffle blocks did not significantly change the current density produced (see figure 3 ).

The gap between the tip of the baffle block and channel wall had a significant effect on the current density produced and on the convergence of the solutions. It was observed that increasing the gap ratio beyond 0.3 did not increase the current density significantly and that gap ratios less than 0.1 did not give converging solutions.

Parametric studies were performed on the effect of the relative humidity and the inlet velocity of the gases using a cell with four baffle blocks and gap ratio of 0.3. It was concluded that the current density was strongly dependent on the relative humidity for low inlet velocities and on the other hand, on the inlet velocity for low relative humidities.

This study suggests that the inlet velocity of the gases should be kept at the maximum values within the investigated range for all the values of the relative humidity and that the relative humidity of the gases should be kept as high as possible within the investigated range of inlet gas velocities. However, the inlet velocity of the gases must also be kept at high values if the cell is operated at low humidities, and the relative humidity of the gases must be kept at high values if the cell is operated at low velocities.

\section{Acknowledgements}

The authors gratefully acknowledge the Mechanical Engineering Department of Gazi University for its financial support and for permission to use the FLUENT software. The authors would also like to thank the Clean Energy Research Center of Gazi University for the Permission to use the PEM fuel cell module of FLUENT 6.2.
Abbreviations
CC Current Collector
GC Gas Channel
GDL Gas Diffusion Layer
$C L \quad$ Catalyst Layer
$P E M \quad$ Proton Exchange Membrane
$F C \quad$ Fuel Cell 


\section{Nomenclature}

A constant in Eq. (1), $R T / 2 \alpha F$

E open circuit voltage, $\mathrm{V}$

F Faraday's constant, 96487 C/equivalent

$i \quad$ current density, $\mathrm{Acm}^{-2}$

$i_{o} \quad$ exchange current density, $\mathrm{Acm}^{-2}$

$i_{n} \quad$ internal current density, $\mathrm{Acm}^{-2}$

$p \quad$ pressure, $\mathrm{Pa}$

$R \quad$ volumetric transfer current, $\mathrm{Am}^{-3}$

$T$ temperature, ${ }^{\circ} \mathrm{C}$

$V \quad$ voltage, $\mathrm{V}$

$v \quad$ gas velocity, $\mathrm{ms}^{-1}$

$x \cdot y, z \quad$ Cartesian coordinate directions

\section{Greek Symbols}

$\phi \quad$ electrical potential, $\mathrm{V}$

\section{References}

Alpat C 2007 Numerical simulation of a proton exchange membrane fuel cell with straight channels. MSc thesis, Gazi University, Ankara

Biyikoglu A, Alpat C Ö 2010 Observation of electrochemical field and the effect of pressure on cell characteristics in a single cell PEMFC. IEESE-5, 5th Int. Ege Energy Symposium and Exhibition (Denizli, Turkey: Pamukkale University)

Biyikoglu A, Oztoprak H 2010 The effect of baffle blocks in a flow channel on PEMFC characteristics. HEFAT-2010, 7th Int. Conf. on Heat Transfer, Fluid Mechanics and Thermodynamics, Antalya, Turkey

Jang J H, Yan W M, Li H Y, Chou Y C 2006 Humidity of reactant fuel on the cell performance of PEM fuel cell with baffle-blocked flow field designs. J. Power Sources 159: 468-477

Larminie J, Dicks A 2003 Fuel cell systems explained 2nd edn. (UK: John Wiley)

Liu H C, Yan W M, Soong C Y, Falin C, Chu H S 2006 Reactant gas transport and cell performance of proton exchange membrane fuel cells with tapered flow field design. J. Power Sources 158: 78-87

Öztoprak H 2007 The Effect of Baffle Blocks in a Flow Channel on Proton Exchange Membrane Fuel Cell Characteristics. MSc thesis, Gazi University, Ankara

Siegel N P 2003 Development and validation of a computational model for a proton exchange membrane fuel cell. PhD thesis, the Faculty of Virginia Polytechnic Institute and State University, Virginia

Soong C Y, Yan W M, Tseng C Y, Liu H C, Falin C, Chu H S 2005 Analysis of reactant gas transport in a PEM fuel cell with partially blocked fuel flow channels. J. Power Sources 143: 36-47

Wang X D, Duan Y Y, Yan W M 2007a Numerical study of cell performance and local transport phenomena in PEM fuel cells with various flow channel area ratios. J. Power Sources 172: 265-277

Wang X D, Duan Y Y, Yan W M 2007b Novel serpentine-baffle flow field design for proton exchange membrane fuel cells. J. Power Sources 173: 210-221

Wang X D, Duan Y Y, Yan W M, Weng F B 2008a Effect of humidity of reactants on the cell performance of PEM fuel cells with parallel and interdigiated flow field designs. J. Power Sources 176: 247-258

Wang X D, Duan Y Y, Yan W M, Peng X F 2008b Effects of flow channel geometry on cell performance of PEM fuel cells wth parallel and interdigitated flow fields. Electrochimica Acta 53: 5334-5343

Yan W M, Li H Y, Chiu P C, Wang X D 2008 Effects of serpentine flow field with outlet channel contraction on cell performance of proton exchange membrane fuel cells. J. Power Sources 178: 174-180 